\begin{tabular}{|c|c|}
\hline Title & $\begin{array}{l}\text { Effects of the Helmholtz Layer Capacitance on the Potential Distribution at Semiconductor/Electrolyte Interface and the } \\
\text { Linearity of the Mott-Schottky Plot }\end{array}$ \\
\hline Author(s) & Uosaki, Kohei; Kita, Hideaki \\
\hline Citation & $\begin{array}{l}\text { Journal of The Electrochemical Society, 130(4), 895-897 } \\
\text { https://doi.org/10.1149/1.2119853 }\end{array}$ \\
\hline Issue Date & 1983 \\
\hline Doc URL & http:/hdl. handle.net/2115/50257 \\
\hline Rights & $\begin{array}{l}\text { (1) The Electrochemical Society, Inc. 1983. A II rights reserved. Except as provided under U.S. copyright law, this work } \\
\text { may not be reproduced, resold, distributed, or modified without the express permission of The Electrochemical Society } \\
\text { (ECS). The archival version of this work was published in J. Electrochem. Soc. } 1983 \text { volume 130, issue 4, 895-897. }\end{array}$ \\
\hline Type & article \\
\hline File Information & JES130-4_895-897.pdf \\
\hline
\end{tabular}

Instructions for use 


\title{
Effects of the Helmholtz Layer Capacitance on the Potential Distribution at Semiconductor/Electrolyte Interface and the Linearity of the Mott-Schottky Plot
}

Kohei Uosaki and Hideaki Kita

J. Electrochem. Soc. 1983, Volume 130, Issue 4, Pages 895-897.

doi: $10.1149 / 1.2119853$

\author{
Email alerting Receive free email alerts when new articles cite this article - sign up in \\ service the box at the top right corner of the article or click here
}

To subscribe to Journal of The Electrochemical Society go to: http://jes.ecsdl.org/subscriptions

(C) 1983 ECS - The Electrochemical Society 
expected to migrate toward the surface when the electrode is under positive bias.

Work is underway to clarify the mechanism of the. above-described effect.

\section{Acknowledgment}

This research was performed under the auspices of the U.S. Department of Energy under Contract No. DE-AC02-76CH00016.

Manuscript submitted July 2, 1982; revised manuscript received Oct. 6, 1982

Any discussion of this paper will appear in a Discussion Section to be published in the December 1983 JourNal. All discussions for the December 1983 Discussion Section should be submitted by Aug. 1, 1983.

Publication costs of this article were assisted by the State University of New York at Stony Brook.

\section{REFERENCES}

1. L. A. Harris and R. H. Wilson, This Journal, 123, 1010 (1976)

2. L. A. Harris, M. E. Gerstner, and R. H. Wilson, ibid., 126, 850 (1979).

3. R. H. Wilson, L. A. Harris, and M. E. Gerstner, ibid. 126, 844 (1979)

4. L. A. Harris and R. Schumacher, ibid., 126, 844 (1979).

5. M. A. Butler, ibid., 126, 338 (1979).

6. D. S. Ginley and M. L. Knotek, ibid., 126, 2163 (1979).

7. M. F. Weber, L. C. Schumacher, and M. J. Dignam, ibid., 129, 2022 (1982).

8. L. J. Van derPauw, Philips Res. Rep., 13, 1 (1958).

9. Z. M. Jarzebsk, "Oxide Semiconductors," Pergamon Press (1972).

10. F. McCrackin, E. Passaglia, R. Stromberg, and $H$. Steinberg, J. Res. Natl. Bur. Standards, A, Physics and Chemistry, 67, No. 4 (1963).

\title{
Effects of the Helmholtz Layer Capacitance on the Potential Distribution at Semiconductor/Electrolyte Interface and the Linearity of the Mott-Schottky Plot
}

\author{
Kohei Uosaki ${ }^{*}$ and Hideaki Kita \\ Department of Chemistry, Faculty of Science, Hokkaido University, Sapporo 060, Japan
}

The knowledge of the potential distribution of the semiconductor/electrolyte interface is essential for understanding the photoelectrochemical behavior of the semiconductor electrode. It is usually assumed that the Helmholtz layer capacitance is so large compared with the space charge layer capacitance that the total capacitance measured can be treated as the space charge layer capacitance and all potential change occurs within the space charge layer, i.e., bandedge is pinned (1). Recently, however, Bard et al. and Wrighton et al. have shown that if a significant amount of surface states is present all the potential change occurs in the Helmholtz layer, i.e., Fermi level is pinned, contrary to the above assumption (2-4). The bandedge pinning and the Fermi level pinning are the two extreme situations of the potential distribution at the semiconductor/electrolyte interface, and usually the applied potential with respect to the flatband potential distributes partly in the space charge layer and partly in the Helmholtz layer (5).

The linearity of the Mott-Schottky plot is often considered to be evidence of the bandedge pinning (6), although De Gryse et al. have shown, by solving the Poisson equation for a depletion layer with Mott-

$$
\begin{aligned}
Q_{s c} & =\epsilon \epsilon_{0}\left(\frac{d \phi}{d x}\right)_{x=0} \\
& = \pm \sqrt{2 \epsilon \epsilon_{0} k T\left\{-\left(N_{D}-N_{A}\right) y_{s}+p_{0}\left(e^{-y_{s}}-1\right)+n_{0}\left(e^{y_{t}}-1\right\}\right)}
\end{aligned}
$$

Schottky approximation (7), that the linearity holds even when the bandedge movement occurs.

In this note we examine the effects of the Helmholtz layer capacitance on the bandedge movement and the linearity of the relation between $1 / C^{2}$ and the applied voltage when no surface states are present by the calculation of the potential dependence of the Helmholtz layer capacitance and the potential change in the Helmholtz layer without many approximations.

- Electrochemical Society Active Member.

Key words: semiconductor, Mott-Schottky plot, Helmholtz layer capacitance.
To obtain the potential distribution of semiconductor/electrolyte interface, the following Poisson equation must be solved (8)

$$
\begin{aligned}
\frac{d^{2} \phi}{d x^{2}}=-\frac{e}{\epsilon_{0} \epsilon}\left[p_{0} \exp \left\{-\frac{e\left(\phi-\phi_{\mathrm{b}}\right)}{k T}\right\}\right. \\
\left.-n_{\mathrm{o}} \exp \left\{\frac{e\left(\phi-\phi_{\mathrm{b}}\right)}{k T}\right\}+N_{\mathrm{D}}-N_{\mathrm{A}}\right]
\end{aligned}
$$

where $e$ is the elementary charge, $\epsilon_{0}$ is the dielectric stant of the semiconductor, $\phi$ and $\phi_{\mathrm{b}}$ are the potential of the semiconductor at $x$ from the semiconductor/electrolyte interface and in the bulk, $p_{0}$ and $n_{0}$ are the concentration of holes and electrons in the bulk, and $N_{\mathrm{D}}$ and $N_{\mathrm{A}}$ are the concentration of donor and acceptor levels, respectively. When the charge at the semiconductor/electrolyte interface is distributed continuously and does not consist of separate point charges, the evaluation gives the following equation for the space charge in the semiconductor, $Q_{s c}$, from the Eq. [1] (8) constant of the vacuum, $\epsilon$ is the relative dielectric con-

Here

$$
y_{\mathrm{s}}=\frac{e\left(\phi_{\mathrm{s}}-\phi_{\mathrm{b}}\right)}{k T}
$$

where $\phi_{\mathrm{s}}$ is the potential of the semiconductor at the surface. The plus sign appears in front of the root when $y_{\mathrm{s}}<0$ and the minus when $y_{\mathrm{s}}>0$. The differential capacitance of the space charge layer, $C_{\mathrm{sc}}$, is obtained by differentiation of Eq. [2] as 


$$
\begin{aligned}
& C_{\mathrm{BC}}=e \sqrt{\frac{e e_{0}}{2 k T}} \\
& \frac{\left|-\left(N_{\mathrm{D}}-N_{\mathrm{A}}\right)-p_{0} e^{-y_{*}}+n_{\mathrm{o}}\right|}{\sqrt{\left.-\left(N_{\mathrm{D}}-N_{\mathrm{A}}\right) y_{\mathrm{S}}+p_{0}\left(e^{-y_{t}}-1\right)+n_{0}\left(e^{y_{0}}-1\right)\right\}}}
\end{aligned}
$$

The measured capacitance, $C$, can be written as

$$
C^{-1}=C_{s e}^{-1}+C_{\mathrm{H}}^{-1}
$$

where $C_{H}$ is the differential capacitance of the Helmholtz layer, and the electrode potential of the semiconductor electrode, $V$, with respect to the flatband potential, $V_{\mathrm{FBP}}$, can be written as

$$
V-V_{\mathrm{FBP}}=\Delta \phi_{\mathrm{sC}}+\Delta \phi_{\mathrm{H}}
$$

where $\Delta \phi_{\mathrm{sc}}$ is the potential change in the space charge layer, i.e., $\Delta \phi_{\mathrm{sc}}=\phi_{\mathrm{b}}-\phi_{\mathrm{S}}$, and $\Delta \phi_{\mathrm{H}}$ is the potential change in the Helmholtz layer, i.e., $\Delta \phi_{\mathrm{H}}=\phi_{\mathrm{H}, \mathrm{v}}-$ $\phi_{\mathrm{H}, \mathrm{FBP}}$, where $\phi_{\mathrm{H}, \mathrm{V}}$ and $\phi_{\mathrm{H}, \mathrm{FBP}}$ are the potential drop in the Helmholtz layer at potential $V$ and at the flatband potential, respectively. By assuming the variation of $C_{H}$ as a function of the electrode potential is negligible, $\Delta \phi_{\mathrm{H}}$ can be expressed as

$$
\Delta \phi_{\mathrm{H}}=Q_{\mathrm{sc}} / C_{\mathrm{H}}
$$

The usual assumption is $\left|\Delta \phi_{s c}\right|>\left|\Delta \phi_{H}\right|$, i.e., the bandedge is pinned. By using Eq. [2], [3], and [7], the ratio of $\Delta \phi_{\mathrm{H}}$ to $\Delta \phi_{\mathrm{H}}+\Delta \phi_{\mathrm{SC}}$, i.e., the total potential change, is calculated as a function of $\left(\Delta \phi_{\mathrm{H}}+\phi \Delta_{\mathrm{sc}}\right)$ by assuming $C_{\mathrm{H}}=10 \mu \mathrm{F} \cdot \mathrm{cm}^{-2}$ and the results are shown in Fig. 1. The contribution of $\Delta \phi_{\mathrm{H}}$ is surprisingly high, particulariy at the potentials near the flatband potential. De Gryse et al. have derived the following equations for n-type semiconductors by using the MottSchottky approximation and demonstrated that the linearity of the Mott-Schottky plot holds even when $C_{H}$ and $\Delta \phi_{\mathrm{H}}$ are taken into account (7)

$$
\begin{gathered}
Q_{\mathrm{sc}}=\frac{2 e_{\epsilon \epsilon}}{N_{\mathrm{D}}}\left(\Delta \phi_{\mathrm{sc}}-\frac{k T}{e}\right) \\
C_{\mathrm{sc}}=\frac{e_{\epsilon \epsilon \mathrm{e}} N_{\mathrm{D}}}{2} \cdot \frac{1}{\sqrt{\Delta \phi_{\mathrm{sc}}-\frac{k T}{e}}} \\
C^{-2}=C_{\mathrm{H}}{ }^{-2}\left\{1+\frac{2 C_{\mathrm{H}^{2}}}{e_{\epsilon \epsilon_{0}} N_{\mathrm{D}}}\left(V-V_{\mathrm{FBP}}-\frac{k T}{e}\right)\right\}
\end{gathered}
$$

The comparison is made between $\Delta \phi_{\mathrm{H}} /\left(\Delta \phi_{\mathrm{se}}+\Delta \phi_{\mathrm{H}}\right)$ obtained by using Eq. [2], [3], and [7] and orie obtained by using Eq. [7] and [8] in Fig. 2. When the potential change is relatively large, two calculations give similar results, but the difference is significant when $\left(\Delta \phi_{\mathrm{sc}}+\Delta \phi_{\mathrm{H}}\right)<0.15 \mathrm{~V}$.

It is interesting to see how $C_{H}$ and $\Delta \phi_{H}$ affect the plot of $\mathrm{C}^{-2} v \mathrm{~s}$. ( $\left.\mathrm{V}-\mathrm{V}_{\mathrm{FBP}}\right)$, i.e., Mott-Schottky plot. The values of $C^{-2}$ obtained by using Eq. [4] and [5] with $C_{H}=10 \mu \mathrm{F} \cdot \mathrm{cm}^{-2}$ and $\infty$ are plotted against $\left(\Delta \phi_{\mathrm{sc}}\right.$ $+\Delta \phi_{\mathrm{H}}$ ) in Fig. 2. $\Delta \phi_{\mathrm{H}}$ is calculated by using Eq. [2], [3], and [7]. The values of $\mathrm{C}^{-2}$ obtained by Eq. [10] with $C_{\mathrm{H}}=10 \mu \mathrm{F} \cdot \mathrm{cm}^{-2}$ are also plotted against $\left(\Delta \phi_{\mathrm{sc}}\right.$ $\left.+\Delta \phi_{H}\right)$ in Fig. 2. In this case $\Delta \phi_{\mathbf{H}}$ is calculated by using Eq. [7] and [8]. Again the difference between the plot with (curve 4) and without (curve 3 ) the approximation becomes significant at small bias potentials. The relation between $C^{-2}$ and $\left(\Delta \phi_{\mathrm{Se}}+\Delta \phi_{\mathrm{H}}\right)$ obtained by Eq. [2], [3], and [7] is linear when potential change is large but curved when $\left(\Delta \phi_{\mathrm{sc}}+\Delta \phi_{\mathrm{H}}\right)$ $<\mathrm{ca} .0 .3 \mathrm{~V}$. The slope of the linear portion of the relation (curve 3 ) is almost the same as that of $\mathrm{C}^{-2}$ vs. $\left(\Delta \phi_{\mathrm{Se}}+\Delta \phi_{\mathrm{H}}\right)$ relation when $C_{\mathrm{H}}$ and $\Delta \phi_{\mathrm{H}}$ are neglected (curve 5) as demonstrated by De Gryse et al. (7).

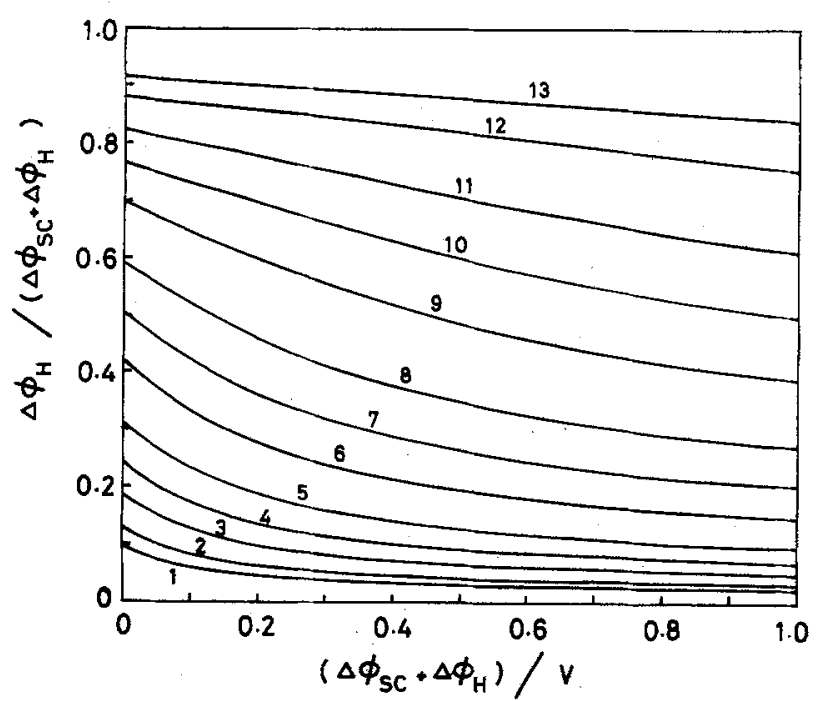

Fig. 1. The ratio of the potential in the Helmholtz layer to the total potential change as a function of the total potential change. $\varepsilon=173 . C_{\mathrm{H}}=10 \mu \mathrm{F} \cdot \mathrm{cm}^{-2}$. Carrier densities are: $1.10^{16} \mathrm{~cm}^{-3}$ $2.2 \times 10^{16} \mathrm{~cm}^{-3}, 3.5 \times 10^{16} \mathrm{~cm}^{-3}, 4.10^{17} \mathrm{~cm}^{-3}, 5.2 \times 10^{17}$ $\mathrm{cm}^{-3}, 6.5 \times 10^{17} \mathrm{~cm}^{-3}, 7.10^{18} \mathrm{~cm}^{-3}, 8.2 \times 10^{18} \mathrm{~cm}^{-3}, 9$. $5 \times 10^{18} \mathrm{~cm}^{-3}, 10.10^{19} \mathrm{~cm}^{-3}, 11.2 \times 10^{19} \mathrm{~cm}^{-3}, 12.5 \times$ $10^{19} \mathrm{~cm}^{-3}, 13.10^{20} \mathrm{~cm}^{-3}$.

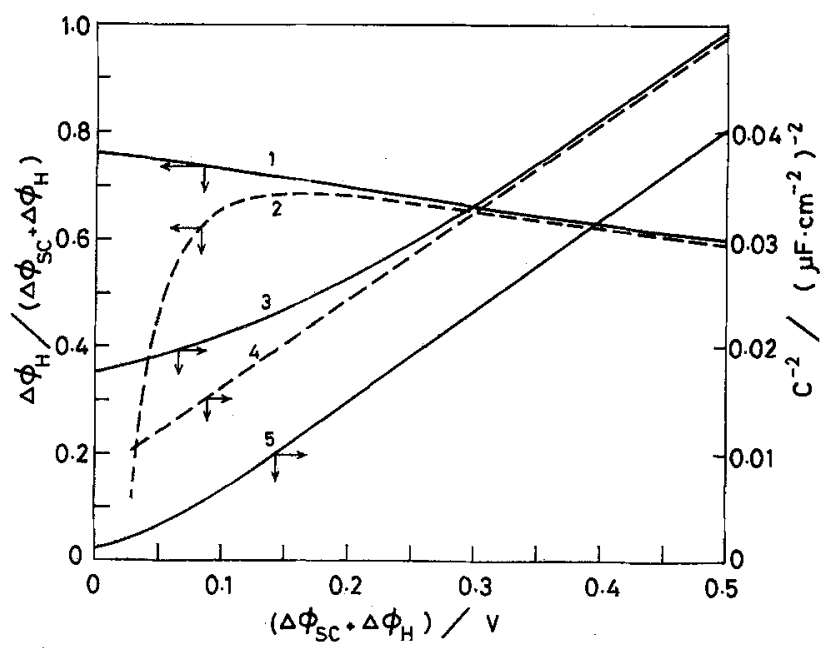

Fig. 2. Dependence of the ratio of the potential change in the Helmholtz layer to the total potential change and of $\mathrm{C}^{-2}$ as a function of total potential change, $\epsilon=173$. Carrier density is 1019 $\mathrm{cm}^{-3}$. 1. $\Delta \phi_{\mathrm{H}} /\left(\Delta \phi_{\mathrm{H}}+\Delta \phi_{\mathrm{se}}\right)$ vs. $\Delta \phi_{\mathrm{H}}+\Delta \phi_{\text {se }}$ calculated by using Eq. [2], [3], and [7], 2. As curve 1 but calculated by using Eq. [7] and [8]. 3. $C^{-2}$ vs. $\Delta \phi_{\mathrm{H}}+\Delta \phi_{\mathrm{sc}}$ calculated by using Eq. $[2],[3],[4],[5]$, and [7], $C_{\mathrm{H}}=10 \mu \mathrm{F} \cdot \mathrm{cm}^{-2} .4$. As curve 3 but calculated by using Eq. [7], [8], and [10]. 5. As curve 3 but $\mathrm{c}_{\mathrm{H}}=\infty$.

Thus, although the linearity between $C^{-2}$ vs. ( $\Delta \phi_{\mathrm{Se}}$ $\left.+\Delta \phi_{H}\right)$ does not hold at relatively small bias and the extrapolation of the linear portion of the relation to $C^{-2}=0$ does not give $V_{F B P}+\frac{k T}{e}-\frac{e_{\epsilon \varepsilon_{0}} N_{D}}{2 C_{H^{2}}}$, the general conclusion of De Gryse et al. is supported, because usually the Mott-Schottky plot is presented for relatively large bias potentials.

The following conclusion can be drawn from the above. (i) $C_{H}$ and $\Delta \phi_{\mathrm{H}}$, i.e., the movement of bandedge, cannot be neglected even when no surface state is present, particularly at highly doped semiconductors. (ii) $C^{-2}$ vs. $V-V_{\mathrm{FBP}}$ plot is linear at relatively large bias potentials but curved at small bias potentials and the slope of the linear portion is almost the same as that of $C^{-2} v s . V-V_{F B P}$ without taking into account $C_{H}$ and $\Delta \phi_{H}$. Thus, the linearity of the Mott-Schottky 
plot at relatively large bias potentials cannot be used as evidence of bandedge pinning. (iii) To obtain an accurate picture of the potential distribution of the semiconductor/electrolyte interface, one must measure the differential capacitance-potential relation for a wide potential range, particularly at small bias potentials, calculate the carrier density from the slope of the linear portion of $C^{-2}$ vs. potential plot, and compare the $\mathrm{C}^{-2} v s$. potential relation calculated by using the carrier density thus obtained and Eq. [2]-[7] for certain values of $V_{\mathrm{FBP}}$ and $C_{\mathrm{H}}$, with the experimentally observed $C^{-2} v s$. potential plot.

\section{Acknowledgment}

This work was partly supported by a grant-in-aid for scientific research, Ministry of Education, Science and Culture, No. 57470001 .

Manuscript submitted Sept. 21, 1982; revised manuscript received Dec. $1,1982$.

Any discussion of this paper will appear in a Discussion Section to be published in the December 1983
Journal. All discussions for the December 1983 Discussion Section should be submitted by Aug. 1, 1983.

Publication costs of this article were assisted by Hokkaido University.

\section{REFERENCES}

1. $R$, $H$ Wilson, in "Semiconductor Liquid-Junction Solar Cells," A. Heller, Editor, p. 67, The Electrochemical Society Softbound Proceedings Series, Princeton, NJ (1977).

2. A. J. Bard, A. B. Bocarsly, F.-R. F. Fan, E. G. Walton, and M. S. Wrighton, J. Am. Chem. Soc, 102, 3671 (1980).

3. F.-R. F. Fan and A. J. Bard, ibid., 102, 3677 (1980).

4. A. B. Bocarsly, D. B. Bookbinder, R. N. Dominey, N. S. Lewis, and M. S. Wrighton, ibid., 102, 3683 (1980)

5. J. O'M. Bockris, K. Uosaki, and H. Kita, J. Appl. Phys., 52, 808 (1981).

6. J. A. Turner and A. J. Nozik, Appl. Phys. Lett., 41, 101 (1982).

7. R. De Gryse, W. P. Gomes, F. Cardon, and J. Vennik, This Journal, 122, 711 (1975).

8. V. A. Myamlin and Yu. V. Pleskov, "Electrochemistry of Semiconductors," Plenum Press, New York (1967). 